\title{
Broad-sense Heritability Estimates for Fruit Color and Morphological Traits from Open-pollinated Half-sib Mango Families
}

\author{
J. Steven Brown', Raymond J. Schnell, Tomás Ayala-Silva, \\ J. Michael Moore, Cecile L. Tondo, and Michael C. Winterstein \\ U.S. Department of Agriculture, Agricultural Research Service, Subtropical \\ Horticulture Research Station, National Germplasm Repository, 13601 Old \\ Cutler Road, Coral Gables, FL 33158
}

Additional index words. Mangifera indica, colorimetric measurments, mango breeding

\begin{abstract}
The visual appearance of mangos is a primary factor in determining consumer acceptance and sale, similar to other fruit and vegetable commodities. Even if the appeal of visual appearance is based on consumer perception rather than on established quality factors, breeders must usually select within the range of acceptance, at least in some countries. Mango selection using multiyear breeding programs is slowly replacing the former method by which most earlier cultivars were selected, namely from chance seedlings either from planned or unplanned crosses. The knowledge of heritability of traits as they are controlled by genetics and experimental design and the effects and interaction of these two sets of factors on achieved gain have become more critical. The use of portable colorimeters has been shown to give repeatable scores in a quantitative, three-dimensional space for fruits and vegetables. In this experiment, we calculated broad-sense heritability estimates for five color traits, three morphological fruit traits, and one disease resistance trait (anthracnose expressed on the fruit). Estimates were found to be relatively high, indicating good potential for improvement through breeding. For nearly all traits measured, variance within families was greater than that among families, illustrating the likely importance of heterozygosity, dominance, and epistasis in these crosses. The careful estimation of heritability and repeatability will help prioritize and increase the efficiency of trait improvement as breeding methods become more sophisticated and competition for funding increases.
\end{abstract}

Mango (Mangifera indica L.) is a traditional, highly esteemed crop in India and Southeast Asia. Over the last 500 years, it has become well established in tropical American locations, including Florida and Hawaii in the United States (Popenoe, 1920). India has been a center of mango cultivation for several thousand years, and named cultivars of recognized superior quality have long been grown there. Knight and Schnell (1994) reviewed the introduction of mangos into Florida and the development of a Florida group of cultivars. Florida mango cultivars are unique, being hybrids between Indian cultivars (primarily monoembryonic) and Southeast Asian cultivars (primarily polyembryonic) with subsequent selection under south Florida conditions.

The mango, like many perennial, cloned fruit tree species, has been considered to be a difficult plant species to improve by breeding

\footnotetext{
Received for publication 10 June 2009. Accepted for publication 31 July 2009 .

We thank the germplasm curatorial and research staff for their help in harvesting and measuring mango fruits for this experiment and Alan Meerow for helpful editorial suggestions.

${ }^{1}$ To whom reprint requests should be addressed; e-mail Steve.Brown@ars.usda.gov.
}

as a result of several intrinsic biological factors (Iyer and Dinesh, 1997; Iyer and Schnell, 2009): 1) a high level of heterozygosity and unpredictable outcomes when crossing parents; 2) a long juvenile period; 3) only one seed per fruit; 4) potentially heavy fruit drop with loss of hybrid fruit; 5) polyembryony in many cultivars; and 6) a large area required for proper assessment of progeny. Nonetheless, mango breeding can be successful as a result of its high level of genetic variability and the ease with which selections can be vegetatively propagated. Because the mango's breeding system favors outcrossing (Iyer and Dinesh, 1997), the proximal growing of numerous genotypes from disparate geographic origins led to the production of many new seedlings that arose from cross-pollination in Florida (Knight and Schnell, 1994; Schnell et al., 2006). Thus, Florida selections did not arise from formal breeding programs; early Florida selections were made by growers and enthusiasts, and historical information is often anecdotal. Although most present-day mango cultivars in India are selected on the Indian subcontinent based mainly on fruit quality, many Florida cultivars have come to be grown widely as commercial cultivars based on broad environmental adaptability (Mukherjee, 1997).
Schnell et al. (2006) analyzed genetic diversity and interrelationships among 203 unique mango cultivars, two selections of $M$. griffithii Hook f., and three M. odorata Griff. accessions maintained at the National Germplasm Repository in Miami, FL, and/or at Fairchild Tropical Botanic Garden in Miami, FL, using 25 microsatellite markers, and found Florida cultivars to more closely related to Indian cultivars than to cultivars from Southeast Asia.

The visual appearance of fresh fruits and vegetables is a very important quality determinant made by the consumer. In Florida, mango color is an important factor in consumer choice (Campbell and Campbell, 2002; Litz and Lavi, 1997), and mangos overlaid with red are especially valued both in fruit consumed in Florida and in fruits shipped to northern markets. In the past, the evaluation of mango color has been subjective, based on visual ratings, and large errors are generally associated with such ratings. The use of the colorimeter has been demonstrated by Ayala-Silva et al. (2005) to accurately quantify fruit color and to differentiate among varieties. Ayala-Silva et al. (2005) measured mango color with a Minolta Chroma Meter CR-400 portable tristimulus colorimeter (Minolta, Osaka, Japan) and evaluated fruit chromaticity in the Commission Internationale d'Éclairage (CIE) L*, a*, and $b^{*}$ color space coordinates. The CIE $\mathrm{L} * \mathrm{a}{ }^{*} \mathrm{~b}$ color space is the most widely used method for measuring and ordering object color, e.g., textiles, inks, paints, plastics, and so on as well as fruits and vegetables. (Gonnet, 1993, 1998) This system records color values in a uniform, three-dimensional color space, in which the $\mathrm{L}^{*}$ coordinate corresponds to a lightness (light versus dark) coordinate, the $\mathrm{a}^{*}$ coordinate corresponds either to red (positive) values or to green (negative) values, and the $b^{*}$ coordinate represents either yellow (positive) values or blue (negative) values. The CIE L*a*b* color space was successfully used to compare fruits from replicated plantings of open-pollinated sibling trees of mango crosses of known maternal parentage and to compare two control clones also planted in replicated plantings (Ayala-Silva et al., 2005). The same maternal half-sib families (MHS) and control clones were also successfully compared for traits assessing quality such as fruit and seed weight, fruit length and width, and anthracnose [Colletotricum gloeosporioides (Penz.) Penz. and Sacc.] resistance.

\section{Materials and Methods}

Our analysis was performed on data from the same experimental trees used by AyalaSilva et al. (2005) using only MHS material. Our analysis combined data from 2 later years, when the trees were more mature (2005 and 2007), for the calculation of heritability estimates for five color traits, fruit weight, fruit length, fruit width, and anthracnose resistance. No data were recorded in 2006 as a result of the effect of 
two hurricanes occurring during the later part of the summer of 2005, causing a total loss of fruiting the next year and the loss of several trees throughout the plots.

Genetic material. Maternal half-sib families of the mango cultivars, Keitt, Tommy Atkins, Tyler Premier, Mamita, White Alfonso, and Sandersha, were evaluated in a field experiment established at the Subtropical Horticulture Research Station in June 1996. The MHS consisted of open-pollinated seedlings, whereas the control clones ('Keitt' and 'Tommy Atkins') were grafted on 'Turpentine' rootstock. The parental clones of the MHS were chosen on the basis of being recognized, valuable commercial types either in Florida, in India, or in other mangogrowing areas of the world. The MHS parents show few interrelationships and their geographical areas of origin cover a large area according to Schnell et al. (2006) and according to GRIN records (Germplasm Resource Information Network, USDA-ARS, Beltsville, MD). The experimental design was a randomized complete block design with three replications. Each experimental plot consisted initially of 10 trees per plot; however, plots were thinned as the trees grew to avoid overcrowding. Additionally, $\approx 10 \%$ of the trees were lost to natural causes, principally as a result of two hurricanes in 2005. Two plots had no trees remaining; these were MHS plots of 'Mamita' and 'White Alphonso'. Fertilization and cultural practices were as recommended for mango production under south Florida conditions (Ruehle and Ledin, 1956).

Data collection. Data for evaluation were collected in 2005 and 2007. Fruits were harvested several times from early June 2005 until mid-Aug. 2005 and again in 2007 during the approximate same period. Experimental plots consisted of up to five trees, and fruits were collected from one to five trees per plot, depending on the number of trees producing fruit that year. Traits measured included total number of fruit produced per tree at each harvest; fruit weight, length, and width; and anthracnose resistance. Fruit weight was measured and recorded in grams using a digital scale. Fruit length and width were measured and recorded in millimeters using a ruler mounted on Plexiglass with one fixed side and one mobile side to enable the fruit to be held in place. Each fruit was rolled until its stable side was found, first in one direction to measure width and second in an orthogonal position to measure length. The mobile side of the Plexiglass holder was pushed to hold the fruit firm. Fruits were measured at the point of maximal width or length. Anthracnose resistance was measured on a numerical rating scale of 1 to 5 with 1 indicating the most severe manifestation and 5 indicating no infection or no breakdown. Percentage descriptions of the classes would follow as such: $1=0-1 \%$ (no disease), $2=1-5 \%$ (slight disease), $2=6-9 \%$ (moderate disease), $4=$ $10-49 \%$ (severe disease), and $5=50-100 \%$ resistance. Pictures in Corkidi et al. (2006) were used as guides. Anthracnose resistance was read from natural infection, because the natural level of inoculum was sufficiently high to give ratings with a normal distribution over the entire experiment. Because our germplasm collection and other experiments were close to this experiment, an overly high level of inoculum was undesired, which would have resulted from additional inoculation.

Skin color measurement. Color measurements of mango fruits were made using a portable CR-400 tristimulus colorimeter (Minolta Chroma Meter CR 400; Minolta, Osaka, Japan) and SpectraMatch software (Minolta, Ramsey, NJ) set to $\mathrm{L}^{*}, \mathrm{a}^{*}, \mathrm{~b}^{*}$ mode. The colorimeter has a beam diameter of $8 \mathrm{~mm}$, three response detectors set at $0^{\circ}$ viewing angle, and a CIE standard illuminant $C$ with diffuse illumination. This illuminant is accepted as having a spectral radiant power distribution closest to reflected diffuse daylight. A white plate was used for calibration $\left(\mathrm{L}^{*}=98.15, C=1.92, h=93.8, \mathrm{a}^{*}=\right.$ $\left.-0.13, b^{*}=1.92\right)$. Each sample was placed on a white table, and $\mathrm{L}^{*}, \mathrm{a}^{*}, \mathrm{~b}^{*}, C$, and $h$ (CIELAB) color measurements were taken in triplicate.

Color values were documented during the harvest periods of the experiment. Mangos were collected each morning for evaluations and harvested at "color break." The mangos were removed from the ground after ensuring that the integrity of the skin was intact with no insect entry or bird damage. Mangos on trees also dropped directly into collector's hand while applying very little pressure. Mangos also dropped off of the tree when the tree was slightly shaken. Fruit evaluations took place within a maximum $24 \mathrm{~h}$ after harvest. Each of the five color values was considered to be a different fruit skin color aspect, or "trait." $\mathrm{L}^{*}$ values indicate lightness [black $\left(\mathrm{L}^{*}=0\right)$ and white $\left.\left(\mathrm{L}^{*}=100\right)\right]$, $\mathrm{a}^{*}$ values indicate redness-greenness [total red $\left(\mathrm{a}^{*}=100\right)$ and green $\left[\mathrm{a}^{*}=(-100)\right]$, and $\mathrm{b}^{*}$ values indicate yellowness-blueness [yellow $\left(b^{*}=100\right)$ and blue $\left[b^{*}=(-100)\right]$. A constant of +60 was added to all $a^{*}$ and $b^{*}$ values recorded to avoid negative values; no negative readings for either measurement were smaller than -60 . Chroma $(C)\left\{C=\left[\left(\mathrm{a}^{*}\right) 2+\right.\right.$ $\left.\left.\left(b^{*}\right) 2\right] 0.5\right\}$ measures color saturation or intensity, and the hue angle $\left[h=\arctan \left(\mathrm{b}^{*}\right)\right.$ $\left.\mathrm{a}^{*}\right)$ ] determines the red, yellow, green, blue, purple, or intermediate colors between adjacent pairs of these basic colors. A lower hue value indicates a redder product. The $\mathrm{L}^{*}, \mathrm{a}^{*}$, and $\mathrm{b}^{*} ; C$; and $h$ values obtained from each mango at the time of sampling were taken from three separate light pulses of the colorimeter. Light pulses were timed to allow movement of the colorimeter to three different locations on each mango. Each record represents one of three readings taken at the shoulder (top), the sinus (middle), and the apex (bottom), spaced equidistantly. Thus, the use of this method allowed for the overall color of each mango to be assessed regardless of small patches of tissue discoloration.

Statistical analysis. Data were analyzed for the MHS trees only, performing analyses on fruits from all families. Clonal data were not included in this analysis, because clones should be genetically identical; therefore, any variance within clones should be the result of environmental effects or genotype $x$ environment interactions. The experiment included only two clones, far too few to give an estimate of clonal variance. Descriptive analysis and test of normality were performed on MHS data to verify assumptions for conditions for analysis of variance (ANOVA). The following transformations (or no transformation) gave the best results to adapt the color data for mixed-model ANOVA: $\mathrm{L}^{*}=$ natural $\log ; \mathrm{a}^{*}=$ no transformation; $\mathrm{b}^{*}=$ natural $\log ; C=$ square root; and $h=$ square root. The fruit measurement data responded best to the following transformations (or no transformation) for a totally random ANOVA to estimate variance components by maximum likelihood: fruit weight $=$ natural $\log$; fruit length $=$ no transformation; fruit width = natural $\log$; anthracnose resistance $=$ no transformation. Although the anthracnose resistance data were scored categorically, its distribution approached the normal distribution sufficiently that a random model could be used to analyze it to estimate heritability.

Broad-sense heritability was estimated using variance components from a mixed or random model analyzed with Proc Mixed of SAS ${ }^{\circledR}$ V9 (SAS Institute, 2002-2008). Broad-sense heritability was estimated, because this is the only useful measure of heritability for outcrossing, vegetatively propagated crops (Wricke and Weber, 1986). Considerable dominance is also usually found to be exhibited in such crops, and complex or inbred breeding populations from multigenerational, controlled crosses are seldom, if ever, produced. Therefore narrow-sense heritability would be of interest only in very specialized cases. Heritability was estimated by calculating the ratio of the variance components:

$\left[\sigma_{\mathrm{f}}^{2}+\sigma_{\mathrm{t}(\mathrm{f})}^{2}\right] /\left\{\left[\sigma_{\mathrm{f}}^{2}+\sigma_{\mathrm{t}(\mathrm{f})}^{2}\right]+\left[\sigma_{\mathrm{fxy}}^{2} / \mathrm{y}\right]+\left[\sigma^{2} / \mathrm{ryf}\right]\right\}$,

where

$\sigma_{\mathrm{f}}^{2}$ is the variance component for variance among families;

$\sigma_{t(f)}^{2}$ is the variance component for variance among trees within families;

$\sigma_{\text {fxy }}^{2} / y$ is the variance component for the variance associated with the interaction of families and years, divided by the number of years; and

$\sigma^{2} /($ ryf) is the variance component for residual variance divided by the number of replications (reps) multiplied by the number of years multiplied by the number of fruit sampled per tree.

Because the experiment was grown in one location only, it was not possible to partition variance as a result of location effects or interactions. All three-way interactions were also contained within the residual error, because it was not possible to fit larger models successfully. Seedling mango trees 
yield very unpredictably from year to year, often yielding no fruit some years and differing each year for the number of fruit produced. The number of fruit sampled per tree depended on the production of a given tree in a specific year. Number of fruit per tree measured was as few as one and as many as 65. Therefore, raw data for mango yield are often very unbalanced, but Proc Mixed does have the ability to analyze unbalanced data effectively by using the Restricted Maximum Likelihood Method (REML). REML incorporates by default the inverses of the variance-covariance matrices both in least squares estimation of fixed effects and in maximum likelihood estimation of random effects. Five different estimates of heritability were calculated using, in one instance, different numbers of years and in four instances different numbers of fruits per tree as divisors for comparison of different estimates of heritability. Postanalysis residual plots were also performed to control for problems of the model in fitting the data. For the estimation of heritability over families for skin color measurements, the variance resulting from the effect of the position on the fruit where the measurement was taken (top, middle, or bottom) was removed by placing a fixed effect in the model. The effect of the position on the fruit where the measurement was taken was removed and mean values were used for the estimation of variance components, because the position measurements are taken from fixed rather than random positions. Such fixed position values would be more valuable in evaluating individual family members relative to one another, i.e., for clonal selection, using firstorder statistics and mean separation. It was thought that one color measurement averaged over the entire fruit would be more valuable for the estimation of heritability than individual measurements for each position of each fruit within families for the three different, fixed positions.

\section{Results and Discussion}

The most interesting point that arose in variance component estimation was the fact that variance resulting from plants within families was generally much larger than the variance among families. This was the case for all color traits (Table 1) except hue angle $(h)$ and for all fruit traits (Table 2) to an even greater extent. The variance among families was generally very small and nonsignificant as determined by the Wald- $Z$ test (not shown) (SAS Institute, 2002-2008). Both tables contain the sources of variance, their estimates, their asymptotic SEs, and lower and upper confidence intervals. The relative sizes of these variance components indicate a larger amount of variability and very likely increased heterozygosity among hybrid progeny within these mango families than between them. Schnell et al. (2006) found the average observed heterozygosity and averaged expected heterozygosity of $208 \mathrm{M}$. indica clones evaluated by 25 microsatellite markers

Table 1. Sources, scales, variance component estimates, SEs of the estimates, and lower and upper confidence intervals for all random terms in the model used for estimating heritability of fruit color traits from colorimeter evaluations of fruit from all maternal half-sib families.

\begin{tabular}{|c|c|c|c|c|c|}
\hline Scale/trait & Source & $\begin{array}{c}\text { Variance } \\
\text { component } \\
\text { estimate }\end{array}$ & SE & $\begin{array}{c}\text { Lower } \\
\text { confidence } \\
\text { interval }\end{array}$ & $\begin{array}{c}\text { Upper } \\
\text { confidence } \\
\text { interval }\end{array}$ \\
\hline \multirow{7}{*}{$\begin{array}{l}\log \left(\mathrm{L}^{*}\right)(\mathrm{L}=\text { lightness- } \\
\text { black to white })\end{array}$} & Year & 0.0835 & 0.1222 & 0.01611 & 136.1887 \\
\hline & Rep & 0.0013 & 0.0048 & 0.00011 & $1.46555 \mathrm{E}+19$ \\
\hline & Family & 0 & - & - & - \\
\hline & Tree (family) & 0.0091 & 0.0035 & 0.0049 & 0.0232 \\
\hline & Year*rep & 0.0046 & 0.0055 & 0.0011 & 0.6680 \\
\hline & Year*family & 0.0050 & 0.0036 & 0.0018 & 0.0449 \\
\hline & Residual & 0.0278 & 0.0009 & 0.0261 & 0.0296 \\
\hline \multirow[t]{7}{*}{$a^{*}\left(a^{*}=\right.$ red to green $)$} & Year & 0 & - & - & - \\
\hline & Rep & 8.5319 & 22.4884 & 0.9900 & $2.64372 \mathrm{E}+11$ \\
\hline & Family & 0.1534 & 9.7794 & - & - \\
\hline & Tree (family) & 19.8932 & 8.9468 & 9.6798 & 61.7683 \\
\hline & Year*rep & 21.8887 & 20.1629 & 6.3623 & 536.9627 \\
\hline & Year*family & 6.1612 & 5.7669 & 1.7669 & 164.7847 \\
\hline & Residual & 38.2827 & 1.2215 & 35.9970 & 40.7943 \\
\hline \multirow{7}{*}{$\begin{array}{l}\log \left(b^{*}\right)\left(b^{*}-\text { yellow }\right. \\
\text { to green })\end{array}$} & Year & 0.01412 & 0.02090 & 0.0027 & 27.3662 \\
\hline & Rep & 0.0002 & 0.0008 & 0.0000 & $2.49319 \mathrm{E}+25$ \\
\hline & Family & 0.0018 & 0.0035 & 0.0003 & 351.8088 \\
\hline & Tree (family) & 0.0061 & 0.0023 & 0.0033 & 0.01534 \\
\hline & Year*rep & 0.0005 & 0.0010 & 0.0000 & 29.1883 \\
\hline & Year*family & 0.0010 & 0.0011 & 0.0002 & 0.1163 \\
\hline & Residual & 0.0141 & 0.0005 & 0.0133 & 0.01502 \\
\hline \multirow{7}{*}{$\begin{array}{l}\text { Sqrt }(\mathrm{C})(\mathrm{C}-\text { color } \\
\text { intensity) }\end{array}$} & Year & 1.0512 & 1.5909 & 0.1967 & 2831.3103 \\
\hline & Rep & 0.0031 & 0.1199 & - & - \\
\hline & Family & 0.0758 & 0.1815 & 0.0095 & 31097685.89 \\
\hline & Tree (family) & 0.3635 & 0.1447 & 0.1895 & 0.9601 \\
\hline & Year*rep & 0.1330 & 0.1636 & 0.0300 & 27.3222 \\
\hline & Year*family & 0.0602 & 0.06806 & 0.0147 & 5.7597 \\
\hline & Residual & 1.1940 & 0.03807 & 1.1229 & 1.2724 \\
\hline \multirow{7}{*}{$\begin{array}{l}\text { Sqrt }(h)(h-\text { hue- } \\
\text { intermediate color } \\
\text { between basic colors })\end{array}$} & Year & 0.9540 & 1.3970 & 0.18394 & $1,574.0022$ \\
\hline & Rep & 0 & - & - & - \\
\hline & Family & 1.1467 & 1.0555 & 0.3335 & 28.0259 \\
\hline & Tree (family) & 1.2081 & 0.7490 & 0.4774 & 6.9120 \\
\hline & Year*rep & 0.01623 & 0.0702 & 0.0014 & $1.01336 \mathrm{E}+27$ \\
\hline & Year*family & 0 & - & - & - \\
\hline & Residual & 12.2822 & 0.3922 & 11.5484 & 13.0886 \\
\hline
\end{tabular}

to be 0.54 and 0.59 , respectively, supporting the observation that heterozygosity would be higher in crosses among mango clones. Ten of 25 microsatellite markers deviated significantly from Hardy-Weinberg (HW) equilibrium, of which eight were higher than 0.5 , the proportion that would be expected under HW equilibrium.

Variance resulting from year was generally small and not significant by the Wald-Z test despite the known variability of mango seedling trees productivity across years. Neither the variance resulting from replications nor the variance resulting from the interaction of the two factors (replication $\times$ years) was significant for color traits. SES of variance components were nonestimable when variance estimates were either equal to zero or very small. Residual variance (model error term) was relatively large for all color factors except the natural $\log$ of $b^{*}$ and the square root of $C$ compared with other sources of variance, whereas residual variances for fruit traits were more in line with other sources of variance or were smaller than other sources of variance. Plots of individual residual error values versus individual predicted values indicated no particular problems with the model fitting the data. When residuals were plotted versus the dependent variable, there was some evidence of heterogeneity in the error variance, becoming slightly larger as the dependent variable became larger, but this is often the case, especially when transformations are necessary to approximate normality. The tests for the fixed effects (not shown), i.e., the position of color reading (top, middle, and bottom), were highly significant for the natural $\log$ of $\mathrm{L}^{*}$, for $\mathrm{a}^{*}$, the natural $\log$ of $b^{*}$, and for the square root of $h$ over families. Only the test for the square root of the $C$ calculations from colorimeter values was nonsignificant over families. When comparing the sources of variance for the four fruit traits, again variance among families was much smaller than variance within families. Variance resulting from years was nonsignificant for all four fruit traits, and for reps, the variance estimate was very near to or equal to zero. Variance estimates resulting from year $\times$ rep interactions and year $\times$ family were generally close to their corresponding SEs, i.e., nonsignificant. Model residual variances were generally relatively small except for fruit length. Individual residual errors plotted versus individual model-predicted values were as would be expected, seeming to fall into a randomly shaped cloud, indicating no 
apparent relationship between the model and the residuals. Again, a small correlation could be detected between the individual predicted values and the individual dependent variable, indicating a small (albeit acceptable) amount of heterogeneity of error variance. From this we can conclude that years, reps, and their interactions contribute similarly rather little to the heritability estimate, but that it is likely slightly upwardly biased.

Because seedling mango trees and some mango clones bear fruit irregularly from year to year, five different heritability estimates were created for each trait based on differing numbers of fruit per tree. All heritability estimates were made on the plot basis. The scale (untransformed, natural log, or square root) was given for each calculation of heritability in Tables 3 and 4 for color and fruit data, respectively. Because the most irregular factor that went into the heritability calculations was the number of fruit per tree, a "basis" calculation was made as if one fruit were being taken from each tree and three additional calculations were made as if 10 , 30 , and 60 fruits were being taken from each tree. More fruit being measured per tree raised the heritability, in this case as a result of larger divisors of the variance components. Another calculation of heritability was made to evaluate the effect of taking another year of data based on the current variance estimates; as would be expected, adding another year's data raised the heritability sufficiently that it would seem worthwhile to consider taking data another year, again in this case, as a result of a higher divisor for the variance components. However, giving sufficient consideration to the experimental design, number of crosses, and families within each cross is certainly worthwhile for the maximum precision of the heritability estimate. Often in vegetatively propagated crops, "repeatability" rather than heritability is considered to be the proper term for the calculation; however, this is more appropriate when vegetatively propagated clones constitute the entries and not seedlings.

The heritability estimates are generally rather high as was found for mango fruit traits by Brettell et al. (2004) and similar to those found in apple (Durel et al., 1998), apricot (Couranjou, 1995), and peach (de Souza et al., 1998), suggesting that the manipulation of these traits by breeding should have excellent potential as is known to be the case in other fruits and vegetables. However, the genetics of inheritance of many quantitatively inherited horticultural traits of mango appears to be unclear. When more large-scale controlled hybridization experiments are undertaken at various mango research centers, such knowledge should be forthcoming and should be very helpful in making decisions on parental selection and experimental design.

Because this experiment was grown at one site only, variance estimates contain withinlocation variance and may be somewhat upwardly biased. It would be worthwhile to
Table 2. Scales and traits, sources, variance component estimates, SES of the estimate, and lower and upper confidence intervals for all random terms in the model used for estimating heritability of morphological traits from fruit evaluations from all maternal half-sib families.

\begin{tabular}{|c|c|c|c|c|c|}
\hline Scale/trait & Source & $\begin{array}{c}\text { Variance } \\
\text { component } \\
\text { estimate }\end{array}$ & SE & $\begin{array}{c}\text { Lower } \\
\text { confidence } \\
\text { interval }\end{array}$ & $\begin{array}{c}\text { Upper } \\
\text { confidence } \\
\text { interval }\end{array}$ \\
\hline \multirow[t]{7}{*}{ Log (fruit weight) } & Year & 0.1238 & 0.2875 & 0.0159 & 15433363 \\
\hline & Rep & 0 & - & - & - \\
\hline & Family & 0 & - & - & - \\
\hline & Tree (family) & 0.1491 & 0.0530 & 0.0825 & 0.3472 \\
\hline & Year*rep & 0.1932 & 0.1414 & 0.0675 & 1.7872 \\
\hline & Year*family & 0.0415 & 0.0343 & 0.01318 & 0.6100 \\
\hline & Residual & 0.0782 & 0.0044 & 0.070301 & 0.0875 \\
\hline \multirow[t]{7}{*}{ Fruit length } & Year & 62.4801 & 284.7256 & 5.490459 & $9.59 \mathrm{E}+33$ \\
\hline & Rep & 0 & - & - & - \\
\hline & Family & 82.3203 & 212.5261 & 9.704396 & $9.34 \mathrm{E}+11$ \\
\hline & Tree (family) & 366.7456 & 154.0601 & 185.6051 & 1036.553 \\
\hline & Year*rep & 344.2146 & 253.0507 & 119.9537 & 3226.843 \\
\hline & Year*family & 56.4193 & 50.48518 & 16.80074 & 1191.668 \\
\hline & Residual & 143.0896 & 7.986329 & 128.6415 & 160.1294 \\
\hline \multirow[t]{7}{*}{$\log$ (fruit width) } & Year & 0.0014 & 0.0201 & - & - \\
\hline & Rep & $2.08 \mathrm{E}-19$ & - & - & - \\
\hline & Family & 0.0007 & 0.0053 & 0 & $6.12 \mathrm{E}+80$ \\
\hline & Tree (family) & 0.0219 & 0.0079 & 0.01202 & 0.0515 \\
\hline & Year*rep & 0.0323 & 0.0234 & 0.0114 & 0.2890 \\
\hline & Year*family & 0.0038 & 0.0034 & 0.0012 & 0.0777 \\
\hline & Residual & 0.0089 & 0.0005 & 0.0080 & 0.0099 \\
\hline \multirow{7}{*}{$\begin{array}{l}\text { Anthracnose } \\
\text { resistance }\end{array}$} & Year & 0.0269 & 0.8849 & — & - \\
\hline & Rep & 0.0981 & 1.0406 & 0.0257 & $1.9 \mathrm{E}+177$ \\
\hline & Family & 0 & - & - & - \\
\hline & Tree (family) & 0.6085 & 0.1977 & 0.3517 & 1.2999 \\
\hline & Year*rep & 1.3685 & 1.3705 & 0.3705 & 54.5479 \\
\hline & Year*family & 0.2265 & 0.1387 & 0.0903 & 1.2572 \\
\hline & Residual & 0.0179 & 0.0010 & 0.01613 & 0.0201 \\
\hline
\end{tabular}

Table 3. Heritability estimates of color traits from colorimeter data based on appropriate random effects from the model. ${ }^{\mathrm{z}}$

\begin{tabular}{|c|c|c|}
\hline \multicolumn{3}{|c|}{ Heritability estimates of color traits on a plot basis } \\
\hline Trait $=$ natural $\log$ of $\mathrm{L}^{*}$ & Estimate & Measurement combinations \\
\hline$\hat{\mathrm{h}}$ (basis) $\mid ;(\mathrm{L}=$ lightness- & 0.5618 & 2 years, 3 reps, 1 fruit/tree \\
\hline$\hat{\mathrm{h}} 1$ |; black to white) & 0.7553 & 2 years, 3 reps, 10 fruit $/$ tree \\
\hline$\hat{\mathrm{h}} 2$ & 0.8224 & 3 years, 3 reps, 10 fruit/tree \\
\hline$\hat{\mathrm{h}}(30)$ & 0.7751 & 2 years, 3 reps, 30 fruit/tree \\
\hline$\hat{\mathrm{h}}(60)$ & 0.7802 & 2 years, 3 reps, 60 fruit/tree \\
\hline Trait $=\mathrm{a}^{*}$ (no transformation) & Estimate & Measurement combinations \\
\hline$\hat{\mathrm{h}}$ (basis) $\mid ;\left(\mathrm{a}^{*}=\right.$ red to green $)$ & 0.5115 & 2 years, 3 reps, 1 fruit/tree \\
\hline$\hat{\mathrm{h}} 1$ & 0.8435 & 2 years, 3 reps, 10 fruit/tree \\
\hline$\hat{\mathrm{h}} 2$ & 0.8899 & 3 years, 3 reps, 10 fruit/tree \\
\hline$\hat{\mathrm{h}}(30)$ & 0.8588 & 2 years, 3 reps, 30 fruit/tree \\
\hline$\hat{\mathrm{h}}(60)$ & 0.8628 & 2 years, 3 reps, 60 fruit/tree \\
\hline Trait $=$ natural Log of $b^{*}$ & Estimate & Measurement combinations \\
\hline$\hat{\mathrm{h}}$ (basis) $\mid ;\left(\mathrm{b}^{*}=\right.$ yellow to green) & 0.7380 & 2 years, 3 reps, 1 fruit/tree \\
\hline$\hat{\mathrm{h}} 1$ & 0.9173 & 2 years, 3 reps, 10 fruit/tree \\
\hline$\hat{\mathrm{h}} 2$ & 0.9433 & 3 years, 3 reps, 10 fruit/tree \\
\hline$\hat{\mathrm{h}}(30)$ & 0.9341 & 2 years, 3 reps, 30 fruit/tree \\
\hline$\hat{\mathrm{h}}(60)$ & 0.9383 & 2 years, 3 reps, 60 fruit/tree \\
\hline Trait $=$ Square root of $\mathrm{C}$ & Estimate & Measurement combinations \\
\hline$\hat{\mathrm{h}}$ (basis) $\mid ;(\mathrm{C}=$ color intensity) & 0.6572 & 2 years, 3 reps, 1 fruit/tree \\
\hline$\hat{\mathrm{h}} 1$ & 0.8978 & 2 years, 3 reps, 10 fruit/tree \\
\hline$\hat{\mathrm{h}} 2$ & 0.9295 & 3 years, 3 reps, 10 fruit/tree \\
\hline$\hat{\mathrm{h}}(30)$ & 0.9228 & 2 years, 3 reps, 30 fruit/tree \\
\hline$\hat{\mathrm{h}}(60)$ & 0.9293 & 2 years, 3 reps, 60 fruit/tree \\
\hline Trait $=$ Square root of $\mathrm{h}$ & Estimate & Measurement combinations \\
\hline$\hat{\mathrm{h}}$ (basis) $\mid ;(\mathrm{h}=$ hue-intermediate & 0.5350 & 2 years, 3 reps, 1 fruit/tree \\
\hline$\hat{\mathrm{h}} 1 \mid$; color between & 0.9200 & 2 years, 3 reps, 10 fruit/tree \\
\hline h $2 \mid$; basic colors) & 0.9452 & 3 years, 3 reps, 10 fruit/tree \\
\hline$\hat{\mathrm{h}}(30)$ & 0.9718 & 2 years, 3 reps, 30 fruit/tree \\
\hline$\hat{\mathrm{h}}(60)$ & 0.9857 & 2 years, 3 reps, 60 fruit/tree \\
\hline
\end{tabular}

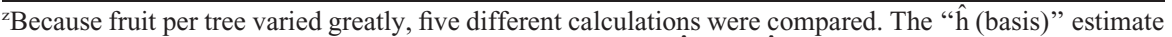
was calculated assuming one fruit per tree was sampled. The $\hat{\mathrm{h}} 1$ and $\hat{\mathrm{h}} 2$ estimates compared the effect of adding one more year of data and assuming that 10 fruit per tree were sampled. The $\hat{h}(30)$ and $\hat{h}(60)$ estimates were based on 2 years and three reps of data, like in the actual experiment, and assuming that 30 and 60 fruit were measured per tree, respectively. 
Table 4. Heritability estimates of fruit traits based on appropriate random effects from the model. ${ }^{2}$

Heritability estimates of fruit traits on a plot basis

\begin{tabular}{|c|c|c|}
\hline Trait $=$ natural $\log$ of fruit weight & Estimate & Measurement combinations \\
\hline$\hat{\mathrm{h}}$ (basis) & 0.8152 & 2 years, 3 reps, 1 fruit/tree \\
\hline$\hat{\mathrm{h}} 1$ & 0.8711 & 2 years, 3 reps, 10 fruit/tree \\
\hline$\hat{\mathrm{h}} 2$ & 0.9102 & 3 years, 3 reps, 10 fruit/tree \\
\hline$\hat{\mathrm{h}}(30)$ & 0.8755 & 2 years, 3 reps, 30 fruit/tree \\
\hline$\hat{\mathrm{h}}(60)$ & 0.8767 & 2 years, 3 reps, 60 fruit/tree \\
\hline Trait $=$ length (no transformation) & Estimate & Measurement combinations \\
\hline$\hat{\mathrm{h}}$ (basis) & 0.8626 & 2 years, 3 reps, 1 fruit/tree \\
\hline$\hat{\mathrm{h}} 1$ & 0.9362 & 2 years, 3 reps, 10 fruit/tree \\
\hline$\hat{\mathrm{h}} 2$ & 0.9566 & 3 years, 3 reps, 10 fruit/tree \\
\hline$\hat{\mathrm{h}}(30)$ & 0.9393 & 2 years, 3 reps, 30 fruit/tree \\
\hline$\hat{\mathrm{h}}(60)$ & 0.9401 & 2 years, 3 reps, 60 fruit/tree \\
\hline Trait $=$ natural $\log$ of width & Estimate & Measurement combinations \\
\hline$\hat{\mathrm{h}}$ (basis) & 0.8693 & 2 years, 3 reps, 1 fruit/tree \\
\hline$\hat{\mathrm{h}} 1$ & 0.9162 & 2 years, 3 reps, 10 fruit/tree \\
\hline$\hat{\mathrm{h}} 2$ & 0.9425 & 3 years, 3 reps, 10 fruit/tree \\
\hline$\hat{\mathrm{h}}(30)$ & 0.9198 & 2 years, 3 reps, 30 fruit/tree \\
\hline$\hat{\mathrm{h}}(60)$ & 0.9208 & 2 years, 3 reps, 60 fruit/tree \\
\hline Trait $=$ anthracnose resistance (no transformation) & Estimate & Measurement combinations \\
\hline$\hat{\mathrm{h}}$ (basis) & 0.8396 & 2 years, 3 reps, 1 fruit/tree \\
\hline$\hat{\mathrm{h}} \mathrm{l}$ & 0.8427 & 2 years, 3 reps, 10 fruit/tree \\
\hline$\hat{\mathrm{h}} 2$ & 0.8893 & 3 years, 3 reps, 10 fruit/tree \\
\hline$\hat{\mathrm{h}}(30)$ & 0.8429 & 2 years, 3 reps, 30 fruit/tree \\
\hline$\hat{\mathrm{h}}(60)$ & 0.8430 & 2 years, 3 reps, 60 fruit/tree \\
\hline
\end{tabular}

${ }^{\mathrm{z}}$ Because the number of fruit per tree varied greatly, five different calculations were compared. The $\hat{\mathrm{h}}$ "basis" estimate was calculated from one fruit per tree. The $\hat{h} 1$ and $\hat{h} 2$ estimates compared the effect of adding one more year of data while assuming that 10 fruit per tree were sampled in all plots. The $\hat{\mathrm{h}}(30)$ and $\hat{\mathrm{h}}(60)$ estimates were based on 2 years and three reps of data, like in the actual experiment, and assuming that 30 and 60 fruit were measured per tree, respectively.

consider replicating the experiment at least in one more location to allow partitioning out location effects and interactions in quantitatively measured characters as well as to balance the risk of losing high numbers of progeny of a certain hybrids and to decrease the SE. Brettell et al. (2004) recommended a minimum of 50 hybrids in each family with a minimum of 30 fruit per family be included, averaging over a given site and a given season so that environmental components of heritability estimates would be based on variation among sites and seasons only. Because our heritability estimates included variance from within one site and two seasons, our estimates were larger than estimates of Brettell et al. (2004) and perhaps somewhat inflated; our results showed nonetheless color traits and fruit traits to be worthwhile breeding goals, even for a smaller experiment. The use of the colorimeter gives reliable quantitative evaluation of fruit color in a three-dimensional space from which heritability data can be calculated with confidence. Evaluating heritability estimates of some categorical traits and some continuous traits will, at times, be difficult, even when careful, repeatable, discrete categories are developed for their classification. Innovative evaluations based on measures of consistency such as that described by Brettell et al. (2004) may be necessary, or methods based on careful classification and analysis may be necessary given the complexity of some mango traits, e.g., flowering. A good deal of knowledge has been amassed concerning the inheritance of various qualitative and quantitative traits and is well presented in the chapter by Iyer and Schnell (2009) of the book edited by R.E. Litz. The performance of such experiments to establish the more important traits from a genetic perspective to estimate heritability adds valuable information for mango breeders for efficiently establishing breeding crosses and selection trials. The use of variance components can also be beneficial when produced from hierarchical or similar experiments for optimally exploring the efficiency of resource allocation. A small example of this was done in this experiment to compare numbers of years and reps. Brown and Glaz (2001) produced a more extensive analysis of this type in sugarcane.

\section{Literature Cited}

Ayala-Silva, T., R.J. Schnell, A.W. Meerow, M. Winterstein, C. Cervantes, and J.S. Brown. 2005. Determination of color and fruit traits of half-sib families of mango (Mangifera indica L.). Proc. Fla State Hort. Soc. 118:253-257.

Brettell, R.I.S., P.R. Johnson, V.J. Kulkarni, W. Müller, and I.S.E. Bally. 2004. Inheritance of fruit characters in hybrid mangoes produced through controlled pollination. Acta Hort. 645: 319-326.

Brown, J.S. and B. Glaz. 2001. Analysis of resource allocation in final stage sugarcane clonal selection. Crop Sci. 41:57-62.

Campbell, C.W. and R. Campbell. 2002. The 'Lancetilla Mango'. Proc. Interamer. Soc. Trop. Hort. 46:35-36.

Corkidi, G., K.A. Balderas-Ruíz, B. Taboada, L. Serrano-Carreón, and E. Galindo. 2006. Assessing mango anthracnose using a new threedimensional image-analysis technique to quantify lesions on fruit. Plant Pathology 55:250-257.

Couranjou, J. 1995. Genetic studies of 11 quantitative characters in apricot. Sci. Hort. 61:61-75.

de Souza, V.A.B., D.H. Byrne, and J.F. Taylor. 1998. Heritability, genetic and phenotypic correlations, and predicted selection response of quantitative traits in peach: II. An analysis of several fruit traits. J. Amer. Soc. Hort. Sci. 123:604-611.

Durel, C.E., F. Laurens, A. Fouillet, and Y. Lespinasse. 1998. Utilization of pedigree information to estimate genetic parameters from large unbalanced datasets in apple. Theor. Appl. Genet. 96:1077-1085.

Gonnet, J.F. 1993. CIELAB measurement, a precise communication in flower colour: An example with carnation (Dianthus caryophyllus) cultivars. J. Amer. Soc. Hort. Sci. 68:499-510.

Gonnet, J.F. 1998. Colour effects of co-pigmentation of anthocyanins revisited. 1: A colorimetric definition using the CIELAB scale. Food Chem. 63:409-415.

Iyer, C.P.A. and M.R. Dinesh. 1997. Advances in classical breeding and genetics in mango. Acta Hort. 455:252-267.

Iyer, C.P.A. and R.J. Schnell. 2009. Breeding and genetics, p. 67-96. In: Litz, R.E. (ed.). The mango botany, production and uses. 2nd Ed. CABI, Wallingford, UK.

Knight, R.J. and R.J. Schnell. 1994. Mango (Mangifera indica L.) introduction and evaluation in Florida and its impact on the world industry. Acta Hort. 341:125-135.

Litz, R.E. and U. Lavi. 1997. Biotechnology, 401445. In: Litz, R.E. (ed.). The mango: Botany, production, and uses. CAB Intl. Pub., Wallingford, UK.

Mukherjee, S.K. 1997. Introduction: Botany and importance, p. 1-19. In: Litz, R.E. (ed.). The mango: Botany, production, and uses. $\mathrm{CAB}$ Intl., New York, NY.

Popenoe, W. 1920. Manual of tropical and subtropical fruits. Macmillan, New York, NY.

Ruehle, G.D. and R.B. Ledin. 1956. Mango growing in Florida. Univ. Florida Agr. Expt. Sta. Bul. 574 .

SAS Institute. 2002-2008. SAS Stat user's guide, Version 9. Cary, NC.

Schnell, R.J., J.S. Brown, C.T. Olano, A.W. Meerow, R.J. Campbell, and D.N. Kuhn. 2006. Mango genetic diversity analysis and pedigree inferences for Florida cultivars using microsatellite markers. J. Amer. Soc. Hort. Sci. 131:214-224.

Wricke, G. and W.E. Weber. 1986. Quantitative genetics and selection in plant breeding. Walter de Gruyter \& Co., Berlin, Germany. 